\title{
UCRL-JC-153085
}

IA WAL NOE IWERMORE WATIONAL LAECAATOAY

\section{RIA Fragmentation Line Beam Dump}

W. Stein

May 2, 2003

2003 Particle Acclerator Conference Portland, Oregon, May 12-16, 2003 
This document was prepared as an account of work sponsored by an agency of the United States Government. Neither the United States Government nor the University of California nor any of their employees, makes any warranty, express or implied, or assumes any legal liability or responsibility for the accuracy, completeness, or usefulness of any information, apparatus, product, or process disclosed, or represents that its use would not infringe privately owned rights. Reference herein to any specific commercial product, process, or service by trade name, trademark, manufacturer, or otherwise, does not necessarily constitute or imply its endorsement, recommendation, or favoring by the United States Government or the University of California. The views and opinions of authors expressed herein do not necessarily state or reflect those of the United States Government or the University of California, and shall not be used for advertising or product endorsement purposes. 


\title{
RIA FRAGMENTATION LINE BEAM DUMP
}

\author{
W. Stein, Lawrence Livermore National Laboratory, Livermore, CA 94551, USA
}

Abstract

The Rare Isotope Accelerator project involves generating heavy element ion beams for use in a fragmentation target line to produce selected ion beams for physics research experiments. The main beam and fission fragments, after passing through the target, are collected and passed along by a series of collecting magnets and a dipole magnet. In the first dipole magnet, the main beam impacts onto a beam dump located on each side of the magnet vacuum chamber. A dump design that involves rotating cylinders and internal water cooling passages has been designed to absorb the glancing impact of the main beam. The beam power designed for is $100 \mathrm{~kW}$ and water cooling is by turbulent sub-cooled forced convection.

\section{INTRODUCTION}

The RIA accelerator beams consist of particles in a range from protons to uranium ions which are impacted on either ISOL or fragmentation line targets. The power along one fragmentation line is expected to be $100 \mathrm{~kW}$ for a uranium ion beam. The beam after passing through the fragmentation target is dumped along the sides of the first dipole magnet.

The beam dump that can absorb the main beam has been designed to fit inside the first dipole magnet of the fragment separator. As the beam is curved through the dipole magnet it may impact either side of the magnet vacuum chamber.

The dump physical design consists of rotating cylinders placed along the sides of the magnet vacuum chamber. The beam is assumed to impact the dump at an angle of 15 degrees and the beam deposited heat is removed by water coolant in the dump copper channels.

\section{BACKGROUND}

The beam for the fragmentation line impacting the fragmentation target has a nominal diameter ${ }^{1}$ of $1 \mathrm{~mm}$ and a power of $100 \mathrm{~kW}$ with an energy of $400 \mathrm{Mev}$ per nucleon. After passing through the fragmentation target the beam emerges with a slight angle spread and passes through the first dipole magnet. The beam is estimated to be at a diameter of $2 \mathrm{~cm}$ as it impacts the beam dump. Selection of desired fission fragments by adjustments in the magnet results in the beam striking either side of the magnet vacuum chamber.

\footnotetext{
* Work sponsored by the U.S. Department of Energy under Contract Nos. DE-AC03-76SF00515 (SLAC) and by Lawrence Livermore National Laboratory under Contract W-7405-Eng-48. Neither the U.S. Government nor the University of California makes any warranty or assumes any legal liability for the accuracy, completeness, or usefulness of the work performed.
}

When the beam strikes the metal of the beam dump, the energy of the particles penetrate and deposit energy according to the relationship:

$$
I=I_{0} e^{-x / a}
$$

With $I_{0}$ equal to the initial intensity, " $x$ " equal to penetration depth, and "a" equal to the interaction length for uranium ions in copper. For $400 \mathrm{Mev}$ per nucleon uranium ions into copper, "a" equals $0.42 \mathrm{~cm}$.

\section{Beam Dump Geometry}

The arrangement of the fragmentation target and the fragment separator is as shown in Fig. 1. The beam dump is located in the first dipole magnet of the separator and consists of two rotating cylinders on each side of the dipole magnet vacuum chamber and is shown schematically in Fig. 2.

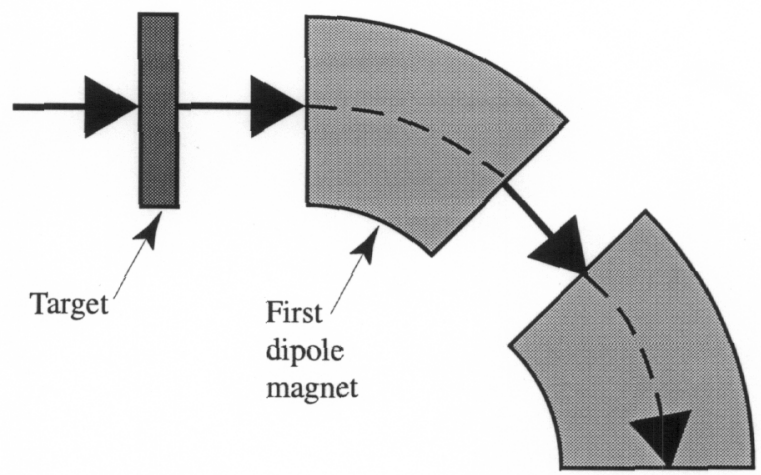

Figure 1: Fragment separator and target schematic.

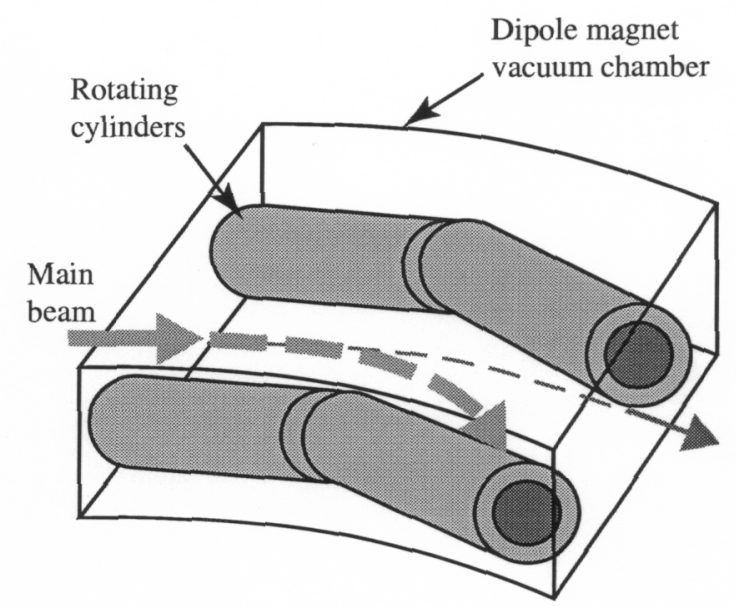

Figure 2: Beam dumps located in the first dipole magnet cavity. 
The dump material is chosen to be copper because of its high thermal conductivity. The figure shows schematically the beam striking the side of the rotating cylinder at an angle estimated to be 15 degrees.

The beam dump cylinders consist basically of a cylinder with coolant channels as shown in Fig. 3. The cylinder outside diameter is $12 \mathrm{~cm}$ and the inner diameter is $11.3 \mathrm{~cm}$. The longitudinal channels are $1 \mathrm{~mm}$ wide, $2 \mathrm{~mm}$ high, and spaced $1 \mathrm{~mm}$ apart.

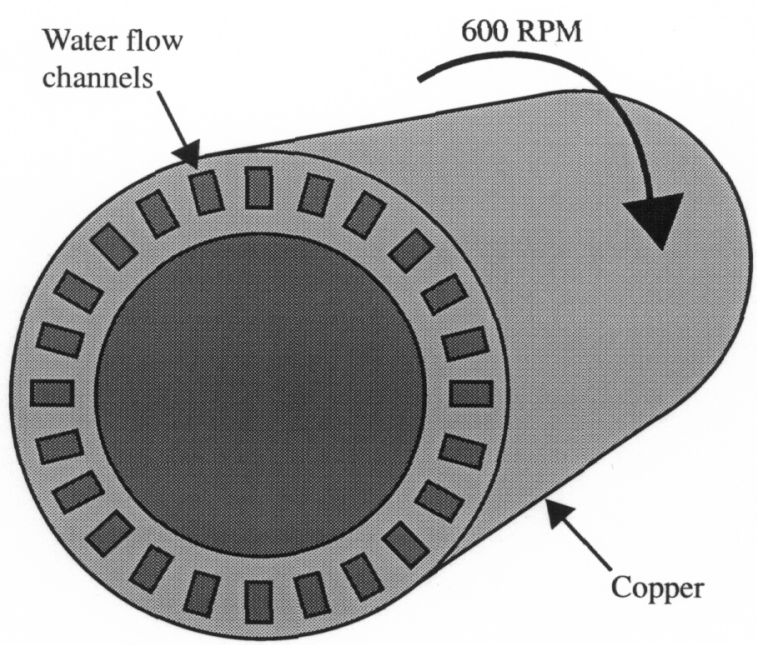

Figure 3: Schematic cross-section of beam dump cylinder design.

The cylinder is assumed to be rotating in order to spread out the beam energy over the greatest possible dump surface area. A rotation speed of 600 RPM will effectively accomplish this.

\section{Heat transfer analyses}

The impact of the $2 \mathrm{~cm}$ diameter beam with a 15 degree angle on the rotating surface will result in the $100 \mathrm{~kW}$ beam spread out over a cylindrical surface that has a diameter of $12 \mathrm{~cm}$ and a length of $7.5 \mathrm{~cm}$. The surface flux is thus $3.6 \mathrm{MW} / \mathrm{m}^{2}$ and this power is deposited into the copper exponentially varying to zero over a depth of $0.5 \mathrm{~cm}$. The water cooling is assumed to have a velocity of $10 \mathrm{~m} / \mathrm{s}$ and a turbulent convective heat transfer coefficient of $20000 \mathrm{~W} / \mathrm{m}^{2}{ }^{\circ} \mathrm{K}$. The heat transfer coefficient is calculated from Nusselt number, $\mathrm{Nu}$, correlations $^{2}$ for turbulent water flow with applicable Reynolds, Re, and Prandtl, Pr, numbers:

$$
N u=0.023(\mathrm{Re})^{0.8} \operatorname{Pr}^{1 / 3}
$$

Inlet water pressure is assumed at 3 atmospheres and the water inlet temperature is $20^{\circ} \mathrm{C}$. For $100 \mathrm{~kW}$ power, the water heats up less than $3{ }^{\circ} \mathrm{C}$ over its flow length.
A two dimensional heat transfer analysis was made to determine peak copper surface temperatures and also annulus water/copper surface temperatures. The LLNL two-dimensional finite element heat transfer code, TOPAZ2D ${ }^{3}$, was used to make the calculations. The code modeled the energy deposition rate per unit volume on the outside region of the copper dump, the thermal conduction heat transfer in the copper, and the convection heat transfer to the $20^{\circ} \mathrm{C}$ water with a convection heat transfer coefficient. Fig. 4 shows a color fringe plot of the temperature profile in a cross section of the beam dump.
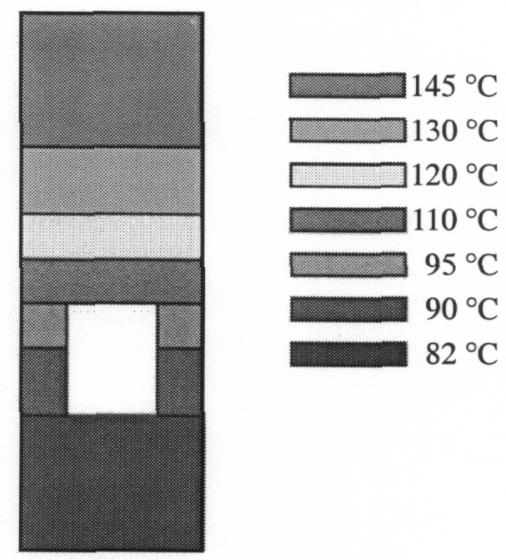

Figure 4: Calculated temperature profile in a dump cross section $\left(20^{\circ} \mathrm{C}\right.$ water $)$.

The plot shows that the peak surface temperature of the copper is $145^{\circ} \mathrm{C}$ and the peak channel wall temperature is $110^{\circ} \mathrm{C}$ with a water bulk temperature of $20^{\circ} \mathrm{C}$.

\section{SUMMARY}

A beam dump for the RIA fragmentation line can be designed to fit inside the first dipole magnet vacuum chamber. The dump consists of rotating cylinders that absorb the $100 \mathrm{~kW}$ beam energy as the beam strikes the cylinders at a small angle. The dump is cooled with forced convection turbulent water flow that maintains coolant channel wall temperatures below the water boiling temperature.

\section{REFERENCES}

[1] J.A. Nolen, et al., "Liquid-lithium cooling for $100 \mathrm{~kW}$ ISOL and fragmentation targets," Nuclear Physics A 701 (2002) 312c-322c.

[2] Frank Kreith, Principles of Heat Transfer, Intex Press, Inc., $3^{\text {rd }}$ edition, 1973, p. 431.

[3] A.B. Shapiro, A.L. Edwards, TOPAZ2D Heat Transfer Code Users Manual, Lawrence Livermore National Laboratory, Livermore, California, UCRLID-104558 (Rev 1), May 1990.

This work was performed under the auspices of the U.S. Department of Energy by the University of California, Lawrence Livermore National Laboratory under Contract No. W-7405-Eng-48. 